\title{
Characteristics of pork belly consumption in South Korea and their health implication
}

\author{
Jee-Hwan Choe ${ }^{1 \dagger}$, Han-Sul Yang ${ }^{2 \dagger}$, Sang-Hoon Lee ${ }^{3}$ and Gwang-Woong Go ${ }^{4 *}$
}

\begin{abstract}
Fresh pork belly is a highly popular meat in South Korea, accounting for $59 \%$ of the approximately $100 \mathrm{~g}$ of meat per capita that is consumed daily. Fresh pork belly offers not only high-quality protein from the lean cuts but also substantial micronutrients including fat-soluble vitamins and minerals. However, fresh pork belly generally consists of about $30 \%$ fat, with saturated fatty acids representing half of this value. Excessive consumption of saturated fatty acids increases total cholesterol, low-density lipoprotein-cholesterol, and triglycerides while decreasing high-density lipoprotein-cholesterol, raising concerns about an increased risk of hyperlipidemia, followed by cardiovascular diseases. In this review, we discuss the consumption and production trends in South Korea, the general characteristics, and health issues related to fresh pork belly to delineate the features of pork production and consumer welfare.
\end{abstract}

Keywords: Pork belly, Pork preference, Pork belly production, Saturated fatty acids, Dyslipidemia, Cardiovascular disease

\section{Introduction}

Pork is the most highly consumed meat in the world (Fig. 1) [1, 2], and global pork markets are expanding and becoming more competitive following recent bilateral free trade agreements [3]. South Korea is one of the highest pork-consuming countries in the world [2], and pork consumption in South Korea has steadily increased in recent years [4]. However, pork production in South Korea does not satisfy consumer demand [4, 5]. In addition, consumers in South Korea have a unique consumption pattern and a strong preference for high-fat cuts such as belly and Boston butt [5-7]. Pork belly (called Sam-gyeop-sal in South Korea) is the most favored primal cut among the various pork cuts. Therefore, the supply of pork belly depends on importation. In contrast, primal low-fat cuts such as loin, tenderloin, picnic shoulder, and ham (pork leg) face surplus inventory problems due to low consumer preference and exporting difficulties [5, 8].

Pork belly not only provides rich flavor and taste but is also a source of high-quality protein, vitamins, and minerals. However, it is also recognized that pork belly is the highest-fat cut among the various primal pork

\footnotetext{
* Correspondence: gwgo@kookmin.ac.kr

†Equal contributors

${ }^{4}$ Department of Food and Nutrition, Kookmin University, Seoul 136-702,

South Korea

Full list of author information is available at the end of the article
}

cuts, and therefore excessive consumption has potential adverse effects on humans, including increasing risk of cardiovascular disease and the metabolic syndrome [9-14]. Therefore, the goal of this article is to review the consumption and production of pork belly in South Korea and the general characteristics of pork belly and to discuss the potential harm to health of excessive consumption of the high fat in pork belly.

\section{Review \\ Consumption and production of pork belly in South Korea}

Pork consumption in South Korea is ranked seventh in the world and third in Asia (Table 1) [2]. In South Korea, pork carcasses are primarily cut into seven parts: Boston butt, picnic shoulder, loin, tenderloin, rib, belly, and ham. Among these primal cuts, belly is the most preferred part in South Korea, followed by Boston butt and rib $[5,8]$. The common characteristic of these pork parts, especially pork belly, is a high fat content (Table 2). On the other hand, South Korean consumers have consumed less loin, tender loin, and ham cut, which are relatively low-fat containing parts. This preference is unique to consumers in South Korea [6, 7]. Indeed, United States consumers favor loin, Boston butt, and rib, and Japanese consumers prefer tenderloin, loin, Boston 


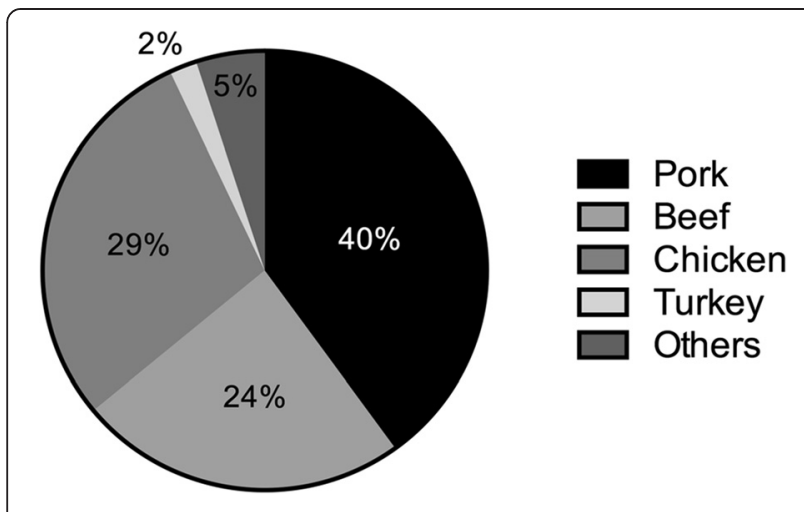

Fig. 1 Meat consumption in the world. Data from report of Pork Checkoff (2012)

butt, and ham. Also, Chinese consumers favor pork ribs and loin [5].

Meat consumption in South Korea has steadily increased, and pork has been the most highly consumed meat (Fig. 2a). Pork consumption, at $20.9 \mathrm{~kg}$ per capita (total $1049 \mathrm{kt}$ ), comprised almost half of the total meat consumption (42.7 kg per capita, total $2148 \mathrm{kt}$ ) in 2013, followed by chicken (11.6 kg per capita, total $580 \mathrm{kt}$ ) and beef (10.3 kg per capita, total $519 \mathrm{kt}$ ) (Fig. 2b and c) [4]. Interestingly, pork consumption in South Korea does not typically trend with pork price. Pork consumption (total pork consumption as well as per capita pork consumption) has slightly increased, although the wholesale pork price has also increased from 2002 to 2010 (Fig. 2d). Moreover, pork consumption remained relatively constant despite a sharp increase in the wholesale pork price from 2008 to 2010. From 2003 to 2008, the inventory rate of pork belly in South Korea was less than 30 \% except 2005, but the inventory rates of other parts such as loin, picnic shoulder, and ham have always more than $30 \%$. A high inventory rate means there is more pork in inventory than is consumed by the customer. The lower inventory rate of pork belly indicates that customers in

Table 1 Top 10 countries in pork consumption per capita $(\mathrm{kg})$

\begin{tabular}{llcccc}
\hline Rank & Country & Year & & & \\
& & 2011 & 2012 & 2013 & 2014 \\
\hline 1 & Montenegro & 45.1 & 46.7 & 38.6 & 44.6 \\
2 & China/Hong Kong/Macau & 38.3 & 40.0 & 41.5 & 42.6 \\
3 & European Union & 41.5 & 40.7 & 40.2 & 42.3 \\
4 & Serbia & 38.0 & 38.6 & 39.5 & 40.0 \\
5 & Belarus & 39.3 & 41.7 & 42.6 & 38.5 \\
6 & Taiwan & 39.7 & 39.0 & 37.7 & 36.9 \\
7 & South Korea & 29.9 & 30.9 & 32.4 & 32.9 \\
8 & Switzerland & 32.5 & 31.6 & 32.6 & 32.8 \\
9 & United States & 26.8 & 26.9 & 27.4 & 26.8 \\
10 & Norway & 26.5 & 25.5 & 25.8 & 25.5 \\
\hline
\end{tabular}

South Korea consumed more belly than other parts of the pig [5]. All of these facts imply that consumers in South Korea prefer pork belly far more than any other parts of the pig, resulting in considerable importation from other countries due to the severe imbalance in the supply and demand of pork belly.

Contrary to the strong preference and high demand for the high-fat cut in South Korea, pork belly (12.2 \%) and Boston butt (6.2\%) are not a highest yield cut, comprising approximately $18.4 \%$ of a pork carcass (Fig. 3). Low-fat pork cuts for which South Korean consumers have a low preference, comprise a higher proportion (about $37.4 \%$ ) of a pork carcass (e.g., ham $17.7 \%$, picnic shoulder $11.2 \%$, and loin $8.5 \%)$ [4, 5, 15]. Consequently, though pork belly is not a low-yield cut, the immoderate preference for pork belly in South Korea has caused an imbalance in the supply and demand of pork belly. Moreover, outbreaks of foot-and-mouth disease (FMD) have a negative effect on South Korea's pork industry since 2000. The small farming operations in South Korea have suffered from a reduced profit due to FMD and increased feed costs, resulting in a loss of small farming operations and an overall decrease in production efficiency [5]. Eventually, overall decrease in pork production efficiency have caused the price rise of pork belly. In addition, contrary to the South Korean market, the global supply of pork, especially the belly cut, is much higher than the global demand, so the South Korean pork market heavily depends on importation from other countries to meet the high domestic demand for pork belly (Fig. 4). The domestic supply rate of pork in South Korea have a tendency to decrease, from $92.8 \%$ in 2003 to $72.8 \%$ in 2013. Furthermore, pork belly comprise approximately $50 \%$ of all imported pork [5]. Although the origin of pork is an important factor to consumers in South Korea, importation of pork belly is inevitable because of the severe imbalance in the pork market in South Korea [5].

\section{General features of pork belly fat for production in South Korea}

Pork belly comprises approximately $12 \%$ of chilled pig carcass, but represents approximately $15-17 \%$ of the total carcass's value (Fig. 3) [4, 15, 16], which means pork belly is an economically principal part of the pig. But, it is obvious that pork belly is an extremely fatty cut among the various primal cuts although an excessive fat content is not favorable to most of consumers and underlies the pathophysiology of many metabolic syndromes and chronic diseases. Previous study showed much higher fat content (approximately 40-50 \%) of pork belly, which is regardless of factors such as genetic background, diet, sex, slaughter weight, and sampling location [17]. Similarly, all the pig breeds available in South Korea have over 
Table 2 Nutritional composition of different pork cuts (raw and cooked) ${ }^{a}$

\begin{tabular}{|c|c|c|c|c|c|c|}
\hline & Energy (kcal/100 g) & Water (g/100 g) & Protein $(\mathrm{g} / 100 \mathrm{~g})$ & Fat $(\mathrm{g} / 100 \mathrm{~g})$ & Ash (g/100 g) & Carbohydrate $(\mathrm{g} / 100 \mathrm{~g})$ \\
\hline \multicolumn{7}{|l|}{ Belly } \\
\hline Raw & 348 & 48.9 & 15.8 & 26.4 & 0.9 & 8.0 \\
\hline Roasted & 493 & 32.7 & 21.9 & 41.1 & 1.0 & 3.3 \\
\hline \multicolumn{7}{|l|}{ Ham } \\
\hline Raw & 235 & 63.6 & 18.5 & 16.5 & 1.1 & 0.3 \\
\hline Roasted & 299 & 45.7 & 38.2 & 14.1 & 0.8 & 1.2 \\
\hline \multicolumn{7}{|l|}{ Loin } \\
\hline Raw & 155 & 66.7 & 22.2 & 3.8 & 1.1 & 6.2 \\
\hline Roasted & 242 & 57.9 & 27.3 & 13.9 & 1.4 & 0.0 \\
\hline \multicolumn{7}{|l|}{ Tender loin } \\
\hline Raw & 186 & 70.8 & 14.1 & 13.2 & 1.4 & 0.5 \\
\hline Roasted & 220 & 53.4 & 40.3 & 5.3 & 1.0 & 0.0 \\
\hline
\end{tabular}

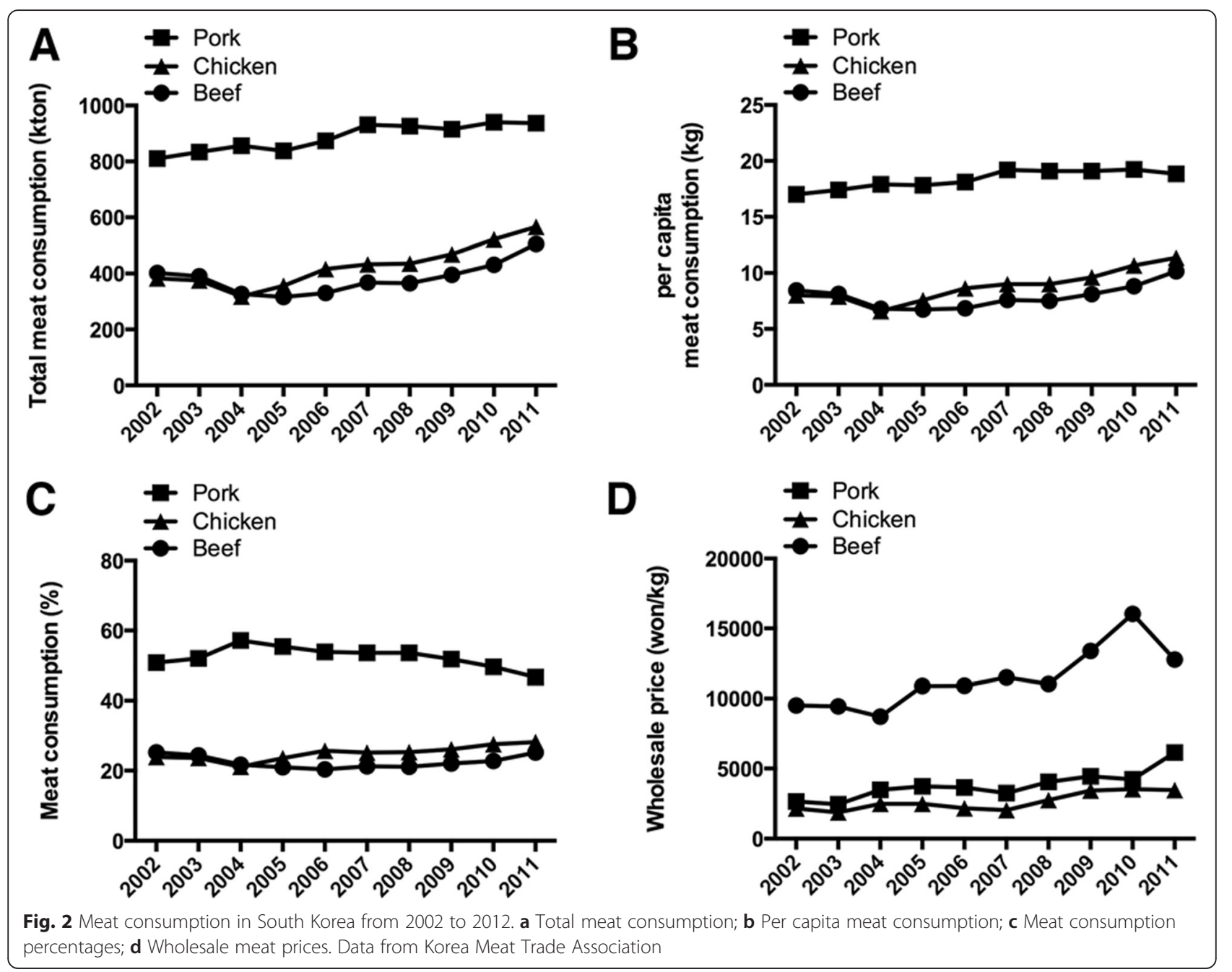




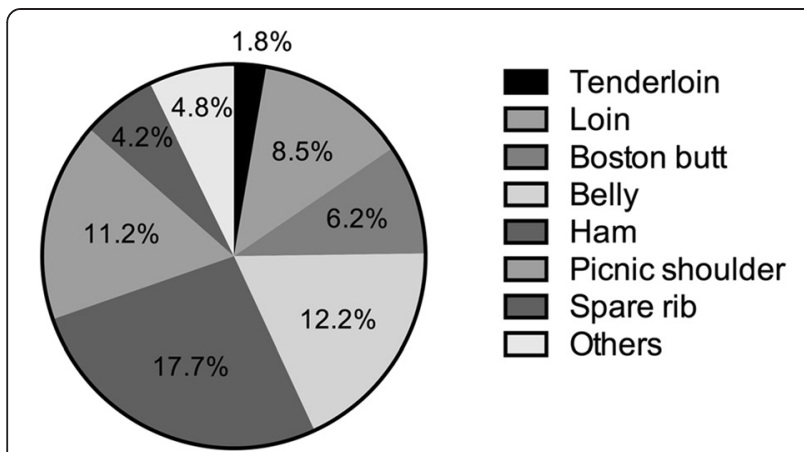

Fig. 3 Average yield (\%) of primal cuts from a pork carcass. Data from Korea Meat Trade Association

$30 \%$ of fat in pork belly cut [18]. Consequently, consumer demand for leaner pork cuts has been increasing in many countries for years [19], resulting in a reduction in pork belly fat content of almost $29 \%$ last 40 years [20, 21]. In sum, the most important characteristics of pork belly are associated with fat and include fat content and fatty acid composition.

Regarding the fat content of pork belly, large differences exist between breeds [22]. Two traditional pig breeds (Berkshire and Tamworth) have a higher fat content, thicker backfat, and less lean meat compared with two modern breeds (Duroc and Large White) [23]. Similarly, the belly cut from Berkshire pigs have a significantly higher fat content [18]. Furthermore, thinner backfat is generally correlated with lower fat content of the pork belly [24]. Genetic selection and/or cross-breeding also improved the growth rate and carcass composition with lower fat and higher lean content [25]. In addition, pig breeds (Landrace, Large White, Pietrain, and Hampshire)

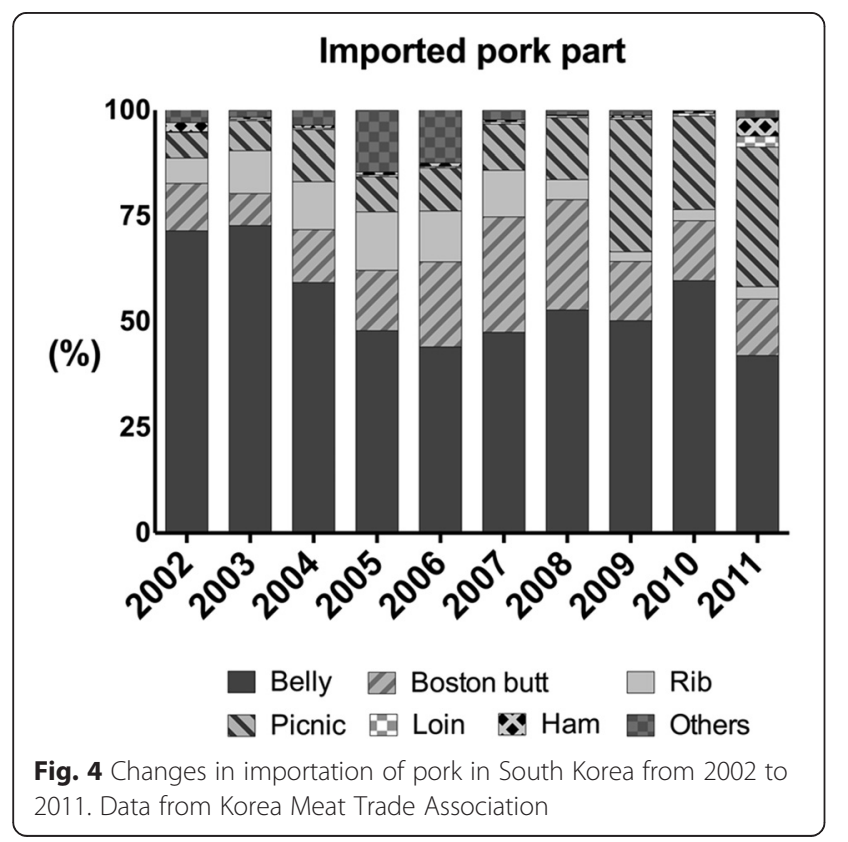

selected for leaner pork production have a superior carcass composition with lower fat and a higher lean content than traditional breeds (Tamworth, Saddleback, and Gloucester Old Spot) [22]. Besides, other factors such as sex, growth rate, and slaughter weight, influence the fat content of the pork belly. Barrows have a higher belly yield, thicker belly and backfat, and higher total fat content in their carcasses than gilts [26, 27]. Pigs with a fast growth rate and heavier slaughter weight also produce more belly portion and have higher fat content in the belly cuts compared with those with a slow growth rate and lighter slaughter weight $[17,23,27-30]$.

Moreover, above factors influencing fat deposition exert modifications on fatty acid composition in pork belly [25]. Previous studies showed that higher fat deposition in the belly is observed in barrows compared to gilts and boars [24]. Moreover, higher fat deposition is generally associated with higher degree of fat saturation [31]. Thus, efforts for higher lean content in carcasses reduce fat deposition and increase fat unsaturation, resulting in a thinner and softer belly [21, 25]. The belly fat of gilts and slow-growing pigs contains a lower proportion of saturated fatty acids (SFAs) such as palmitic acid (C16:0) and stearic acid (C18:0), along with a higher proportion of linoleic acid (C18:2n-6), and of total polyunsaturated fatty acids (PUFAs). Consequently, the belly cuts from gilts and slow-growing pigs have higher PUFA/SFA ratio and $n-6 / n-3$ ratios [21].

There is an interesting difference of perception about pork belly (or bacon) between Western countries and South Korea, because favored fatty acid profiles of pork belly are aiming different marketability. In Western countries, they primarily process pork belly as bacon, which is the cured and processed form of belly. On the contrary, consumers in South Korea favor grilled or roasted bellies rather than cured or processed bacon [32]. This difference led producers in each region to established distinct production strategy, i.e. Western consumer preferred higher saturation in pork belly. In fact, belly cut obtained from thick belly had the highest processing yields through the smoking and cooking processes. On the other hand, bacon from thin belly had the lowest slicing yields and a lack of crispiness [20]. During pork processing, a leaner belly with a lower degree of fat saturation is associated with problems related to increased handling, processing, and slicing difficulties; reduced bacon yield; and production of unattractive bacon [33, 34]. In particular, the firmness of the belly fat shows a strong positive correlation with the proportions of palmitic acid and stearic acid, whereas negative correlation with the proportions of linoleic acid, linolenic acid, and other PUFAs [21, 33, 35]. In addition, products with a high degree of unsaturated fats are more prone to rancidity during storage, resulting in reduced shelf-life $[18,21]$. Based on these features, increasing unsaturation of 
pork belly is not desirable in Western countries. However, strategies for reducing fat content and increasing the degree of unsaturation in pork bellies does not affect marketability in South Korea.

\section{Benefits and risks of pork belly consumption}

It is well known that pork meat provides not only highquality protein from the lean cuts but also key micronutrients including fat-soluble vitamins and minerals. Thus, it is commonly accepted that meat provides a means for reducing malnutrition and increasing food security in developing countries $[9,36]$. However, in developed countries where high fat and excessive calories are regularly consumed, meat consumption may underlie the pathophysiology of non-communicable diseases including cardiovascular disease, obesity, dyslipidemia, and cancer [9-14]. Indeed, high fat intake through consuming red meat such as fresh pork belly likely accelerates these adverse health conditions. Controversy exists as to the role of red meat consumption in the increased risk of developing public health-related diseases. Interpretation of results from prospective cohort studies has created uncertainty about the role of animal fat in the development of atherosclerosis and cardiovascular disease [37]. Nonetheless, numerous researchers have reported that colon cancer and cardiovascular disease are highly associated with excessive red meat consumption [10-12, 38]. The relationship between a high consumption of fat, a significant feature of pork belly, and dyslipidemia and cardiovascular disease is largely undisputed.

Unprocessed pork belly contains approximately $48 \%$ fat and $39 \%$ lean content [32]. Fat content is, in general, greatest in the dorsal portion of the belly and lowest in the ventral portion. The most abundant fatty acids in pork belly are monounsaturated fatty acids (MUFAs) followed by SFAs and PUFAs (47 \%, $36 \%$, and $16 \%$, respectively) [21]. It is the proportions of specific fatty acids in the diet that are associated with the causes and prevention of coronary heart disease (CHD) rather than the total amount of fat [39-44]. It is particularly evident that there is a strong association between the incidence of CHD and SFAs or foods containing SFAs such as red meat. When SFAs in the diet are replaced by MUFAs or PUFAs, the risk of CHD is significantly reduced $[45,46]$. SFAs are known to elevate the low-density lipoprotein (LDL)/high-density lipoprotein (HDL) ratio, potentiating foam cell formation and atherosclerosis [42, 47, 48]. In addition, after the American Heart Association (AHA) recommended decreasing SFA intake in 1961, there was a dramatic decline in CHD in Western countries [49]. It is noteworthy that replacing SFAs with MUFAs or PUFAs more successfully reduces the incidence of CHD than simply reducing total fat consumption [47]. Likewise, the LDL-cholesterol level and the total cholesterol/ HDL-cholesterol ratio were reduced when SFAs were substituted with MUFAs. The PUFA/SFA ratio is an important indicator of CHD with a lower PUFA/SFA ratio correlating with a greater risk of CHD [45]. Fresh pork belly has a PUFA/SFA ratio of 0.48 and an n-6/n3 ratio of 17.98 . Values of 0.45 or above for the PUFA/ SFA ratio and 4.0 or below for the $n-6 / n-3$ ratio have been recommended in the United Kingdom.

The Korean Dietary Reference Intakes recommend that energy from fat should not exceed $25 \%$ of total daily intake. These guidelines also suggest that saturated fat intake should not exceed $4.5-7.0 \%$ and total cholesterol intake should be less than $300 \mathrm{mg} /$ day for adults [50]. Additionally, according to AHA guidelines, the SFA intake should be limited to $7-10 \%$ of daily calories [51]. However, approximately $48 \%$ fat in $100 \mathrm{~g}$ of fresh pork belly contains 441 calories, which certainly exceeds the guidelines in general. Koreans consumed $24 \mathrm{~g}$ of pork belly per day during 2011, resulting in the intake of $11.5 \mathrm{~g}$ (104 calories) of fat, $4.1 \mathrm{~g}$ (37 calories) of SFAs, and $17.3 \mathrm{mg}$ of cholesterol from this meat alone [4]. Furthermore, if these calculations are adjusted for age, there is little doubt that Korean adults consume a significant amount of fresh pork belly, which will increase the risk of non-communicable diseases. Approximately 100-200 g of fresh belly meat alone will exceed the guideline limits of SFA, cholesterol, and total fat intake. Therefore, most health organization guidelines limit red meat consumption chiefly to aid in reducing SFA and cholesterol consumption. In conclusion, excessive consumption of pork bellies as part of an unbalanced diet is highly likely to lead to impaired nutrient intake and abnormal fatty acid profiles, thereby negatively affecting long-term health.

\section{Changes in pork consumption patterns in South Korean households}

As mentioned previously, the strong preference and high demand for pork belly led to an imbalance in the supply and demand of pork production in South Korea. These imbalances increased the price of pork belly and depreciated the relative economic value of other parts of the pig. These trends are clearly not viewed as progress in the pork industry. The data from Statistics Korea in Table 3 clearly show that, although pig productivity has been slightly improved due to increase in the number of post-weaned piglets per sow per year (PSY) and the number of marketed pigs per sow per year (MSY), pig production cost per $100 \mathrm{~kg}$ live weight have been greatly increased from 2008 to 2012 (exception for 2011 due to FMD outbreaks), leading to decrease in net income. Because pork belly is the most consumed pork part, pork producers shift the loss in net income into pork 
Table 3 Pig production cost per $100 \mathrm{~kg}$ live weight and pig productivity

\begin{tabular}{lllllll}
\hline & Year & & & & \\
& 2008 & 2009 & 2010 & 2011 & 2012 & 2013 \\
\hline Production cost $^{\mathrm{a}}$ & 221,893 & 238,748 & 247,783 & 302,231 & 293,577 & 290,094 \\
Net income $^{a}$ & 59,542 & 88,281 & 40,389 & 143,455 & 9,139 & $-27,950$ \\
PSYb $^{\text {b }}$ & 19.8 & 20.5 & 20.1 & 19.4 & 20.1 & 20.8 \\
MSYc $^{\text {M }}$ & 17.3 & 18.1 & 17.8 & 17.6 & 18.1 \\
\hline
\end{tabular}

${ }^{a}$ Korean won

${ }^{\mathrm{b}}$ Number of post weaned piglet per sow per year

${ }^{c}$ Number of marketed pigs per sow per year

belly price, resulting in pork price have been increased continuously. It has become more difficult that consumers in South Korea consume the pork belly due to too much expensive. Furthermore, research has indicated that excessive consumption of fat, including consumption of pork belly, threatens public health in South Korea. Taken together, the most desirable shifts in pork consumption would be to decrease that of pork belly and to increase that of other leaner cuts.

As seen in Table 4, a recent survey showed a meaningful change in the purchase patterns of pork cuts in South Korean households (2015 agricultural forecast from the Korean Rural Economic Institute). From 2011 to 2014, the proportion of pork belly purchased among the pork cuts decreased from $36.5 \%$ to $32.2 \%$, whereas that of picnic shoulder and ham increased by $2.5 \%$ and that of loin and tenderloin increased by $1.1 \%$. In addition, according to this report, these tendencies are not temporary and consuming low-fat primal cuts should continue to be promoted not only for consumer health reasons but also for stabilization of the pork industry.

\section{Conclusions}

Pork is the source of high-quality protein, vitamins, and minerals. Consumers in South Korea also favor pork rather than chicken and beef. Especially, they strongly prefer pork belly, the highest fat and the lower yield cut. The unique and strong consumption pattern in South Korea caused severe imbalance between demand and supply of pork belly, resulting in heavily depend on

Table 4 Changes in purchase patterns of primal pork cuts in South Korean households

\begin{tabular}{lllll}
\hline Cut of meat & Year & & & \\
& 2011 & 2012 & 2013 & $2014^{\mathrm{a}}$ \\
\hline Belly & $36.5 \%$ & $33.9 \%$ & $31.8 \%$ & $32.2 \%$ \\
Boston butt & $12.5 \%$ & $12.6 \%$ & $13.0 \%$ & $12.2 \%$ \\
Rib & $6.0 \%$ & $6.6 \%$ & $7.3 \%$ & $6.5 \%$ \\
Picnic shoulder and ham & $21.0 \%$ & $23.4 \%$ & $23.8 \%$ & $23.5 \%$ \\
Loin and tenderloin & $4.7 \%$ & $4.5 \%$ & $5.2 \%$ & $5.8 \%$ \\
Other & $19.4 \%$ & $19.0 \%$ & $19.0 \%$ & $19.8 \%$ \\
\hline
\end{tabular}

${ }^{\mathrm{a}}$ Data were collected from January to November 2014 import from foreign countries. In addition, excessive consumption of pork bellies as part of an unbalanced diet is highly likely to lead to impaired nutrient intake and abnormal fatty acid profiles, thereby negatively affecting long-term health. These implies that preference for pork belly in South Korea have potential risk to domestic pork industry development and consumers health. However, the meaningful change is recently observed that purchase of belly decreased and consuming low-fat primal cuts increased. These shifts in pork consumption can help not only stabilization of the pork industry but also consumer welfare in South Korea.

\section{Competing interests}

The authors declare that they have no competing interests.

\section{Authors' contributions}

GWG planned and wrote the layout of this article. JHC and HSY primarily wrote the manuscript. SHL is also involved in writing. JHC, HSY and SHL checked and edited the manuscript. GWG finally reviewed the manuscript. All authors carefully read and revised the final manuscript and agree to publish in this form.

\section{Author details}

'Department of Food Bioscience and Technology, Korea University, Seoul 136-701, South Korea. ${ }^{2}$ Division of Applied Life Science Graduate School (BK21 plus), Gyoungsang National University, Jinju 660-701, South Korea. ${ }^{3}$ Department of Nutritional Science and Food Management, Ewha Womans University, Seoul 120-750, South Korea. ${ }^{4}$ Department of Food and Nutrition, Kookmin University, Seoul 136-702, South Korea.

Received: 8 April 2015 Accepted: 28 May 2015

Published online: 09 June 2015

\section{References}

1. Pork Checkoff. Quick Facts: The pork industry at a Glance. 2009.

2. Pork Checkoff. Pork stats. 2014.

3. Oh SH, Whitley NC. Pork production in China, Japan and South Korea. Asian Australas J Anim Sci. 2011;24:1629-36.

4. KMTA. 2014. Available from: www.kmta.or.kr.

5. Oh SH, See MT. Pork preference for consumers in China, Japan and South Korea. Asian Australas J Anim Sci. 2012;25:143-50.

6. Cho S, Park B, Ngapo T, Kim J, Dransfield E, Hwang I, et al. Effect of meat appearance on South Korean consumer's choice of pork chops determined by image methodology. J Sens Stud. 2007;22:99-114.

7. Ngapo T, Martin JF, Dransfield E. International preferences for pork appearance: I. Consumer choices. Food Qual Prefer. 2007;18:26-36.

8. Vonada ML, Bidner BS, Belk KE, McKeith FK, Lloyd WR, O'Connor ME, et al. Quantification of pork belly and Boston butt quality attribute preferences of South Korean customers. J Anim Sci. 2000;78:2608-14.

9. Daniel CR, Cross AJ, Koebnick C, Sinha R. Trends in meat consumption in the USA. Public Health Nutr. 2011;14:575-83. 
10. Aune D, Chan DS, Vieira AR, Navarro Rosenblatt DA, Vieira R, Greenwood DC, et al. Red and processed meat intake and risk of colorectal adenomas: a systematic review and meta-analysis of epidemiological studies. Cancer Causes Control. 2013;24:611-27.

11. Rohrmann S, Overvad K, Bueno-de-Mesquita HB, Jakobsen MU, Egeberg R, Tjønneland $\mathrm{A}$, et al. Meat consumption and mortality-results from the European Prospective Investigation into Cancer and Nutrition. BMC Med 2013;11:63.

12. Chan DS, Lau R, Aune D, Vieira R, Greenwood DC, Kampman E, et al. Red and processed meat and colorectal cancer incidence: meta-analysis of prospective studies. PLoS One. 2011;6(6):e20456.

13. Larsson SC, Wolk A. Meat consumption and risk of colorectal cancer: a meta-analysis of prospective studies. Int J Cancer. 2006;119:2657-64.

14. Cosgrove M, Flynn A, Kiely M. Consumption of red meat, white meat and processed meat in Irish adults in relation to dietary quality. $\mathrm{Br} \mathrm{J}$ Nutr. 2005;93:933-42.

15. NHERI. 2012. Available from: www.nheri.re.kr.

16. Stiffler DM, Chant JL, Kinsman DM, Kotula AW. Indexes of leanness in commercial bacons. J Anim Sci. 1975:41:1611-7.

17. Mann JE, Mandigo RW, Burson DE, Dennis E, Garza R. Factors affecting bacon color and composition. Nebraska Swine Reports. 2002:83:66-9.

18. Kang HS, Seo KS, Kim KT, Nam KC. Comparison of pork quality characteristics of different parts from domesticated pig species. Korean J Food Sci Anim Resour. 2011;31:921-7.

19. Marcoux M, Pomar C, Faucitano L, Brodeur C. The relationship between different pork carcass lean yield definitions and the market carcass value. Meat Sci. 2007:75:94-102.

20. Person RC, McKenna DR, Griffin DB, McKeith FK, Scanga JA, Belk KE, et al. Benchmarking value in the pork supply chain: processing characteristics and consumer evaluations of pork bellies of different thicknesses when manufactured into bacon. Meat Sci. 2005:70:121-31.

21. Correa J, Gariepy C, Marcoux M, Faucitano L. Effects of growth rate, sex and slaughter weight on fat characteristics of pork bellies. Meat Sci. 2008;80:550-4

22. Lambe N, Simm G. Animal breeding and genetics. In: Jensen WK, editor. Encyclopedia of Meat Science. Oxford, UK: Elsevier; 2004.

23. Wood J, Nute G, Richardson R, Whittington F, Southwood O, Plastow G, et al. Effects of breed, diet and muscle on fat deposition and eating quality in pigs. Meat Sci. 2004;67:651-67.

24. Fredeen HT. Yields and dimensions of pork bellies in relation to carcass measurements. J Anim Sci. 1980;51(1):59-68.

25. Schinckel A, Mills S, Weber T, Eggert J. A review of genetic and nutritional factors affecting fat quality and belly firmness. Proc Natl Swine Improv Fed Annu Mtg, Nashville, TN. 2002;27:89-113.

26. Newcom DW, Baas TJ, Mabry JW, Goodwin RN. Genetic parameters for pork carcass components. J Anim Sci. 2002;80:3099-106.

27. Correa JA, Faucitano L, Laforest JP, Rivest J, Marcoux M, Gariépy C. Effects of slaughter weight on carcass composition and meat quality in pigs of two different growth rates. Meat Sci. 2006;72:91-9.

28. Kim GW. Analysis of carcass quality grades according to gender, backfat thickness and carcass weight in pigs. J Anim Sci Technol. 2012;54:29-33.

29. Park MJ, Park BC, Ha DM, Kim JB, Jang KS, Lee DH, et al. Effects of increasing mearket weight of finishing pigs on backfat thickness, incidence of the "Caky-fatty" belly, carcass grade, and carcass quality traits. J Anim Sci Technol. 2013;55:195-202.

30. Park BC, Ha DM, Park MJ, Jin SK, Park JH, Lee CY. Effects of the decreased carcass grade of finishing pigs due to increasing market weight carcass quality traits and physicochemical and sensory characteristics of the loin and belly. J Anim Sci Technol. 2013;55:203-10.

31. Wood JD, Jones RCD, Bayntun JA, Dransfield E. Backfat quality in boars and barrows at $90 \mathrm{~kg}$ live weight. Anim Prod. 1985;40:481-7.

32. Nam KC, Jo C, Lee M. Meat products and consumption culture in the East. Meat Sci. 2010;86:95-102

33. Trusell KA, Apple JK, Yancey JW, Johnson TM, Galloway DL, Stackhouse RJ. Compositional and instrumental firmness variations within fresh pork bellies. Meat Sci. 2011:88:472-80

34. Sather AP, Jones SDM, Robertson WM, Zawadski S. Sex effects on fat hardness meter readings of market weight pigs. Can J Anim Sci. 1995;75:509-15.

35. Eggert JM, Belury MA, Kempa-Steczko A, Mills SE, Schinckel AP. Effects of conjugated linoleic acid on the belly firmness and fatty acid composition of genetically lean pigs. J Anim Sci. 2001;79:2866-72.
36. McNeill S, Van Elswyk ME. Red meat in global nutrition. Meat Sci. 2012;92:166-73

37. Kaluza J, Wolk A, Larsson SC. Red meat consumption and risk of stroke: a meta-analysis of prospective studies. Stroke. 2012:43:2556-60.

38. Huxley RR, Ansary-Moghaddam A, Clifton P, Czernichow S, Parr CL, Woodward $M$. The impact of dietary and lifestyle risk factors on risk of colorectal cancer: a quantitative overview of the epidemiological evidence. Int J Cancer. 2009;125:171-80

39. Flock MR, Kris-Etherton PM. Diverse physiological effects of long-chain saturated fatty acids: implications for cardiovascular disease. Curr Opin Clin Nutr Metab Care. 2013;16:133-40.

40. Sauder KA, Skulas-Ray AC, Campbell TS, Johnson JA, Kris-Etherton PM, West SG. Effects of omega-3 fatty acid supplementation on heart rate variability at rest and during acute stress in adults with moderate hypertriglyceridemia. Psychosom Med. 2013;75:382-9.

41. Lefevre M, Mensink RP, Kris-Etherton PM, Petersen B, Smith K, Flickinger BD Predicted changes in fatty acid intakes, plasma lipids, and cardiovascular disease risk following replacement of trans fatty acid-containing soybean oil with application-appropriate alternatives. Lipids. 2012;47:951-62.

42. Pedersen JI, James PT, Brouwer IA, Clarke R, Elmadfa I, Katan MB, et al. The importance of reducing SFA to limit CHD. Br J Nutr. 2011;106:961-3.

43. Van Horn L, McCoin M, Kris-Etherton PM, Burke F, Carson JA, Champagne CM, et al. The evidence for dietary prevention and treatment of cardiovascular disease. J Am Diet Assoc. 2008:108:287-331.

44. Gebauer SK, Psota TL, Kris-Etherton PM. The diversity of health effects of individual trans fatty acid isomers. Lipids. 2007;42:787-99.

45. Jakobsen MU, O'Reilly EJ, Heitmann BL, Pereira MA, Bälter K, Fraser GE, et al. Major types of dietary fat and risk of coronary heart disease: a pooled analysis of 11 cohort studies. Am J Clin Nutr. 2009;89:1425-32.

46. Mensink RP, Zock PL, Kester AD, Katan MB. Effects of dietary fatty acids and carbohydrates on the ratio of serum total to HDL cholesterol and on serum lipids and apolipoproteins: a meta-analysis of 60 controlled trials. Am J Clin Nutr. 2003:77:1146-55

47. Baum SJ, Kris-Etherton PM, Willett WC, Lichtenstein AH, Rudel LL, Maki KC, et al. Fatty acids in cardiovascular health and disease: a comprehensive update. J Clin Lipidol. 2012;6:216-34.

48. Flock MR, Green MH, Kris-Etherton PM. Effects of adiposity on plasma lipid response to reductions in dietary saturated fatty acids and cholesterol. Adv Nutr. 2011;2:261-74.

49. Micha R, Mozaffarian D. Saturated Fat and cardiometabolic risk factors, coronary heart disease, stroke, and diabetes: a fresh look at the evidence. Lipids. 2010;45:893-905.

50. KDRls. The Korean Nutrition Society; 2010. Available from: http://www.kns.or.kr

51. Pearson TA, Palaniappan LP, Artinian NT, Carnethon MR, Criqui MH, Daniels SR, et al. American Heart Association Guide for Improving Cardiovascular Health at the Community Level, 2013 update: a scientific statement for public health practitioners, healthcare providers, and health policy makers. Circulation. 2013:127:1730-53.

\section{Submit your next manuscript to BioMed Central and take full advantage of:}

- Convenient online submission

- Thorough peer review

- No space constraints or color figure charges

- Immediate publication on acceptance

- Inclusion in PubMed, CAS, Scopus and Google Scholar

- Research which is freely available for redistribution 